\title{
Estimation of Air Velocity for Levitation of Microparticles for Air Quality Control
}

\author{
Vinh N. T. Pham ${ }^{1}$, Van Nguyen², Nguyen Duy Vy, $\mathbf{V y}^{3, *}$ \\ ${ }^{1}$ Ho Chi Minh City University of Education, Ho Chi Minh City, Vietnam \\ ${ }^{2}$ NEOhouse Architecture Construction JSC., Ho Chi Minh City, Vietnam \\ ${ }^{3}$ Laboratory of Applied Physics, Advanced Institute of Materials Science, Ton Duc Thang University, \\ Ho Chi Minh City, Vietnam \\ ${ }^{4}$ Faculty of Applied Sciences, Ton Duc Thang University, Ho Chi Minh City, Vietnam
}

Received: 24 December 2019

Accepted: 22 February 2020

\begin{abstract}
Using Newton's first law of motion and geometrical analysis, we performed an estimation of force balance on a microparticle to figure out the conditions for dust levitation and ventilation. The dust particle is assumed to be a sphere pushed by a uniform upward airflow. The gravitational force pulls it downward. The velocity-dependent drag force is assumed to be zero. The results show that the minimal speed of air is proportional to the square root of both the particle mass density and size. To visualize the formula, five samples of dust have been used involving hazardous PM2.5 dust. The minimal speed for PM2.5 dust at room temperature is $\sim 22 \mathrm{~cm} / \mathrm{s}$, which is just $10 \%$ higher than the "breeze" speed of air commonly known in the industry. This analysis could be adopted to other more complex shapes of microparticles, such as ellipsoids and cylinders corresponding to various kinds of dust. The result could also help figure out optimal and effective ventilation and filtration systems toward saving energy in air quality control.
\end{abstract}

Keywords: microparticle, airflow, ventilation

\section{Introduction}

Affection of microparticles and bioaerosols on human health receives has seen important interest in recent years [1-4]. Arising from industrial zones, motor vehicles, or living activities, these particles float and are inhaled, causing negative effects on human health [3-7]. Studying to reduce these affects, beside examining the origin, moving laws, and distribution of microparticles

*e-mail: nguyenduyvy@tdtu.edu.vn in various regions, their direct filtration is also crucial for a cleaner indoor environment. As a result, filtration systems are widely adopted in working and living spaces.

The physics of micro-sized particles floating in ambient air are important in both fundamental physics and application. The chaotic behavior is usually described by the Brownian motion of a particle under random affections of external forces that result from the floating force of air or liquid, the collisions of nearby particles, gravitational force, or even electrostatic force if the particle is not electrically neutral. On practical applications, the density and kinetics of these particles 
are of interest, especially for air quality control in factories and living spaces [2, 7] - especially the PM10 [7] and PM2.5 [8-13] dusts that could have hazardous effects on human health.

There are several forces exerted on a floating particle that affect its motion. Gravitational force pulls it to the ground while the buoyancy force levitates it up. In static air with negligible air fluctuation, it gradually builds up on the ground. However, due to the thermal fluctuation of the external environment and human activities, the particles continuously collide. In spaces where the passive cooling is adopted, a ventilation fan and a filtration system are usually equipped.

The structure and effectiveness of filtration systems have been examined in many studies $[1,2]$. In this work, we examine the role of the speed of air on the particle levitation for ventilation. Newton's first law of motion is adopted on the microparticle to figure out the force balance on it. Then an estimation on minimum speed of airflow will be shown. The speed should reach some value $v_{0}$ to maximize the levitation and filtration effectiveness. The obtained formula presents a dependence on the particle size and mass density of the speed squared.

The formulation is general and could be applied to any shape of microparticle. In such cases a more complex geometrical analysis should be used. Therefore, this simple analysis is basic for studying the motion of microparticles.

\section{Calculation Model}

To derive a formula showing the force that airflow exerts on the particle, these assumptions are adopted [Fig. 1]:

- The dust shape is a sphere with radius $r$, mass density $\rho$, and mass $m_{d}$ with $m_{d}=(4 / 3) \pi r^{3} \rho$.

- The airflow has a density $\rho_{0}$, moving continuously and uniformly with velocity $v_{0}$.

- The airflow exerts a uniform pressure $P$ on every area element (perpendicular to the flow direction) of the hemisphere, i.e., $P=d F / d \mathrm{~s}=F_{\text {air }} / S$ where $S=\pi r^{2}$ (as shown in Fig. 1a).
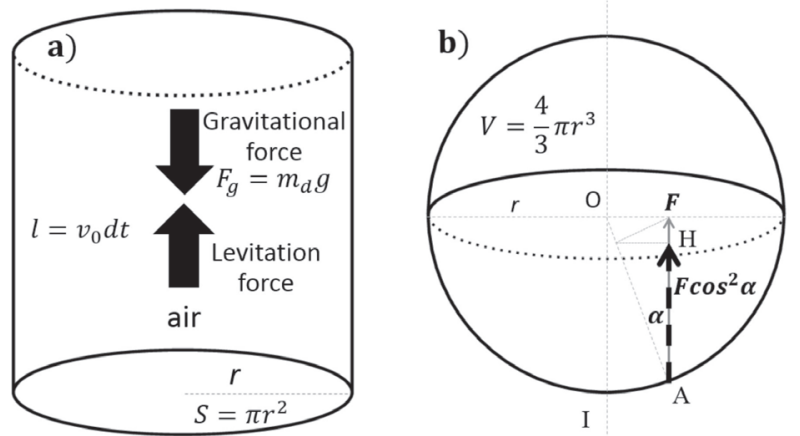

Fig. 1. Forces exerted on a microparticle that is assumed to be a sphere.
- The drag force, which is proportional to the velocity of microparticles [14], $F_{\text {drag }} \propto F_{\text {drag }} v$, is negligible.

For the particle to be levitated, the upward acceleration must be positive, i.e., from Newton's first law of motion:

$$
\vec{a}>0 \Leftrightarrow \sum \vec{F}>0 \Leftrightarrow F_{a i r}-F_{g}>0
$$

\section{A Rough Estimation}

A particle of mass $m_{d}$ suffers a gravitational force [see Fig. 1b)]:

$$
F_{g}=m_{d} g=\frac{4}{3} \pi r^{3} \rho g
$$

...where $g \approx 9.8 \mathrm{~m} / \mathrm{s}^{2}$ is the gravitational acceleration and an airflow levitation force (see Fig. 1a)):

$$
F=m \frac{|d \mathbf{v}|}{d t}
$$

...where $d v$ is the velocity change of the air element. We assume that the initial velocity of the air element is $v_{0}$ and after colliding and transferring momentum to the dust, its final velocity is $v_{f}=0$. Therefore, $|d \mathbf{v}|=v_{0}-$ $v_{f} m$ is the mass of the air volume that passes through cross-section $S$ within the time interval $d t$ :

$$
m=V \rho_{0}=S v_{0} d t \rho_{0}
$$

Then,

$$
F_{\text {air }}=m \frac{|d \mathbf{v}|}{d t}=S v_{0} d t \rho_{0} \frac{v_{0}}{d t}=S v_{0}^{2} \rho_{0}=\pi r^{2} v_{0}^{2} \rho_{0}
$$

The condition (1) to be satisfied so that the airflow could elevate the dust particle is $F_{\text {air }}>F_{g}$. Then,

$$
\pi r^{2} v_{0}^{2} \rho_{0}>\frac{4}{3} \pi r^{3} \rho g \Leftrightarrow v_{0}^{2}>\frac{4}{3}\left(\frac{\rho}{\rho_{0}}\right) r g
$$

This means the minimum velocity should be $v_{0} ; \frac{2}{\sqrt{3}} \sqrt{\frac{\rho}{\rho_{0}} r g}$

\section{A Finer Analysis}

In Eq. (2) we assumed that all air elements in the area $S$ exert the same force on the cross section of the dust particle. This could be corrected more because the levitating force that an air element exerts on the dust at position $\mathrm{A}$ is smaller than that at I (Fig. 1b). The net force is proportional to $\mathrm{AH} / \mathrm{AF}=\cos ^{2} \alpha$, or $F_{i}=F \cos ^{2} \alpha \Rightarrow P_{i}=P \cos ^{2} \alpha$. 
Therefore, the force element exerting on the area $d s=r^{2} \sin \alpha d \alpha d \beta$ would be:

$$
\begin{gathered}
d F_{i}=P_{i} d s=P \cos ^{2} \alpha d s=P \cos ^{2} \alpha r^{2} \sin \alpha d \alpha d \beta \\
=\operatorname{Pr}^{2} \cos ^{2} \alpha \sin \alpha d \alpha d \beta
\end{gathered}
$$

Integration over the semi-sphere with $\alpha, \beta=[0: \pi]$, we have:

$$
F_{\text {air }}=\int d F_{i}=P \cdot r^{2} \int_{0}^{\pi} \cos ^{2} \alpha \sin \alpha d \alpha \int_{0}^{\pi} d \beta=\frac{2}{3} \pi r^{2} P
$$

In comparison to Eq. (2), the force is now reduced by a factor of $2 / 3$, i.e.: $F_{\text {air }}=(2 / 3) \pi r^{2} P=P=(2 / 3) S P$. Therefore, the r.h.s of Eq. (3) should be modified as:

$$
\frac{2}{3} v_{0}^{2}>\frac{4}{3} \frac{\rho}{\rho_{0}} r g \Leftrightarrow v_{0}^{2}>2 \frac{\rho}{\rho_{0}} r g
$$

...where $\rho=1.204 \mathrm{~kg} / \mathrm{m}^{3}$ at $20^{\circ} \mathrm{C}$, meaning that for the dust particle to be elevated the air velocity squared must be higher than value $2\left(\rho / \rho_{0}\right) r g$ or $2\left(\rho / \rho_{0}\right) d g$, where the diameter $d$ is commonly used for the particle size. As an example, the PM2.5 [PM10] with $d \leq 2.5$ [10] $\mu \mathrm{m}$ are of essential interest due to their direct negative effects on the human respiratory system.

\section{Results and Discussion}

The analysis in this case is simple thanks to the spherical symmetry of the dust. However, for other microparticles with more elaborate shapes, the analysis will be involved - especially the integration in Eq. (5). Hence, the minimum $v_{0}$ will correspond to the case of the particle least exposed to airflow, i.e., ellipsoids and cylinders that are vertically aligned.

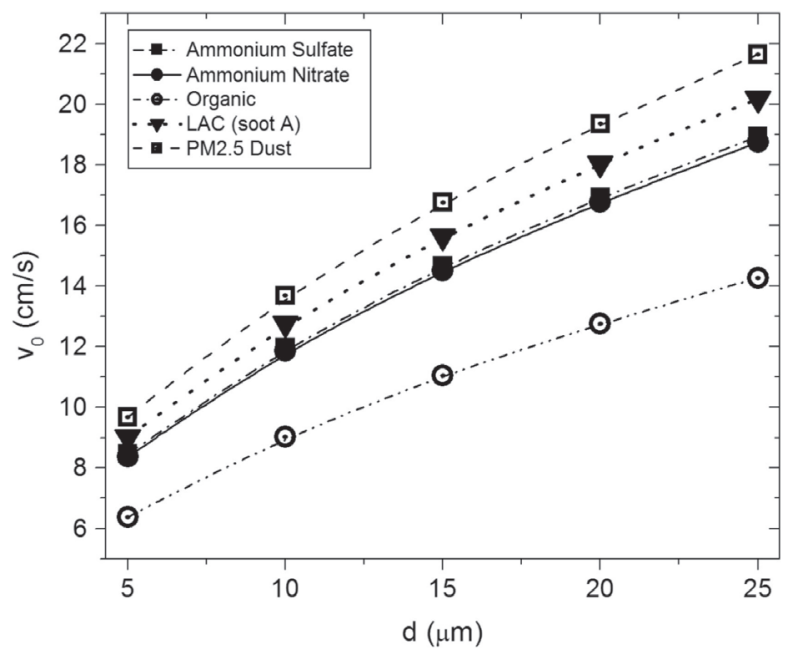

Fig. 2. Minimum speed of air $v_{0}$ from Eq. (6) to levitate the dust for five samples.
It is straightforward to visualize Eq. (6) provided that the particle parameters are known. Nevertheless, due to the diversity of dust characteristics, e.g., physical/chemical composition, specific mass, and size, it is challenging to figure out entirely the factor that is dependent on both the dust specific mass and size. Therefore, we use five samples of dust with the mass densities studied in a recent work (Ref. 15, Table 3), where $\rho^{\prime}=1.0-2.3 \mathrm{~g} / \mathrm{cm}^{3}$ : ammonium sulfate $\left(1.76 \mathrm{~g} / \mathrm{cm}^{3}\right)$, ammonium nitrate $\left(1.72 \mathrm{~g} / \mathrm{cm}^{3}\right)$, organics $\left(1.0 \mathrm{~g} / \mathrm{cm}^{3}\right)$, LAC (light-absorbing carbon, $\left.2.0 \mathrm{~g} / \mathrm{cm}^{3}\right)$, and PM2.5 $\left(2.3 \mathrm{~g} / \mathrm{cm}^{3}\right)$, and the estimated velocity of the airflow in Fig. 2.

The figure shows the sub-linear increase in the minimum speed $v_{0}$ (Eq. 6) with particle size. For example, $v_{0}$ should reach $22 \mathrm{~cm} / \mathrm{s}$ to levitate PM2.5 dust. These values for the speed of air $\left(v_{0}\right)$ from a ventilation/ filtration fan help for setting up an optimal cleaning/ filtration system since a high value of $v_{0}$ could attract more dust into space or excite other dust sources. These factors reduce the effectiveness of the filtration system and increase energy costs.

\section{Conclusions}

Although a simple model has been adopted, the obtained results have shown a quantitative agreement with the practical results in the experiment. The important achievement is the formula relating the minimal velocity of the airflow and the density and size of the dust. It shows that the minimum speed of air is proportional to the square root of both the particle mass density and size so that it could levitate the microparticle. The calculation has been confirmed using the data from a recent experiment and presents a consistence with the values used in practical applications, i.e., industry. The calculation method could be extended for different microparticles with various shapes and mass densities.

\section{Acknowledgements}

The authors acknowledge the fruitful comments from both the reviewers and editors. We also thank Dr. Phan Quang Thang (Osaka Prefecture University) for significant discussions.

\section{Conflict of Interest}

The authors declare no conflict of interest.

\section{References}

1. SUBLETT J.L. Effectiveness of air filters and air cleaners in allergic respiratory diseases: A review of the recent 
literature. Current Allergy and Asthma Reports, 11 (5), 395, 2011.

2. LIU G., XIAO M., ZHANG X., GAL C., CHEN X., LIU L., PAN S., WU J., TANG L., CLEMENTS-CROOME D. A review of air filtration technologies for sustainable and healthy building ventilation. Sustainable Cities and Society, 32, 375396, 2017.

3. BALYAN P., GHOSH C., DAS S., BANERJEE B.D., Spatio-Temporal Variations of Indoor Bioaerosols in Different Socio-Economic Zones of an Urban Metropolis. Polish Journal of Environmental Studies, 28 (6), 4087, 2019.

4. PENKAŁA M., OGRODNIK P., ROGULAKOZŁOWSKA W., Silica Dust as an Additive in Concrete with Proven Impact on Human Health. Polish Journal of Environmental Studies, 28 (6), 4057, 2019.

5. DEMKOVÁ L., OBOŇA J., ÁRVAY J., MICHALKOVÁ J., LOŠÁK T., Biomonitoring Road Dust Pollution Along Streets with Various Traffic Densities. Polish Journal of Environmental Studies, 28 (5), 3687, 2019.

6. SALIH Z., AZIZ F., Heavy Metal Accumulation in Dust and Workers' Scalp Hair as a Bioindicator for Air Pollution from a Steel Factory. Polish Journal of Environmental Studies, 29 (2), 1805, 2020.

7. JIN X., FAN J., NIU H., LING P., YU Q. Analysis of Sources and Concentrations of Heavy Metal Contents in PM10 over a Four-Season Cycle in a Heavily Industrialised City in China. Polish Journal of Environmental Studies, 28 (5), 3227, 2019.

8. XIE Z., LI Y., QIN Y., ZHENG Z. Optimal Allocation of Control Targets for PM2.5 Pollution in China's BeijingTianjin-Hebei Regions. Polish Journal of Environmental Studies, 28 (5), 3941, 2019.

9. WANG Y., ZHANG H., ZHAI J., WU Y., CONG L., YAN G., ZHANG Z. Seasonal Variations and Chemical
Characteristics of PM2.5 Aerosol in the Urban Green Belt of Beijing, China. Polish Journal of Environmental Studies, 29 (1), 361, 2020.

10. STEDMAN J.R., GRICE S., KENT A. COOKE S. GISbased models for ambient PM exposure and health impact assessment for the UK. Journal of Physics: Conference Series, 151, 012002, 2009.

11. BROWN K.W., SARNAT J.A., KOUTRAKIS P. Concentrations of PM2.5 mass and components in residential and non-residential indoor microenvironments: The sources and composition of particulate exposures study. Journal of Exposure Science and Environmental Epidemiology, 22, 161172, 2011.

12. MEMHOOD T., TIANLE Z., AHMAD I., LI X., SHEN F., AKRAM W., DONG L. Variations of PM2.5, PM10 mass concentration and health assessment in Islamabad, Pakistan. IOP Conference Series: Earth and Environmental Science, 133, 012031, 2018

13. LIU Z., GAO W., YU Y., HU B., XIN J., SUN Y., WANG L., WANG G., BI X., ZHANG G., XU H., CONG Z., HE J., XU J., WANG Y. Characteristics of PM2:5 mass concentrations and chemical species in urban and background areas of China: emerging results from the CARE-china network. Atmospheric Chemistry and Physics, 18 (12), 88498871, 2018.

14. MENDOZA-ARENAS J.J., PERICO E.L.D., FAJARDO F. Motion of a damped oscillating sphere as a function of the medium viscosity. European Journal of Physics, 31 (1), 129141, 2009.

15. MOLENAR J.V. Theoretical analysis of PM2.5 mass measurements by nephelometry-110. 2003. Available online: http://vista.cira.colostate.edu/improve/publications/ graylit/014_AerosolByNeph/AerosolbyNeph.pdf (accessed on 24 December 2019). 